\title{
REINVENTAREA SOCIALISTĂ A MODERNISMULUI. TRADUCERILE ÎN LIMBA ROMÂNĂ ALE ROMANULUI RURAL*
}

\begin{abstract}
Expansiunea - deopotrivă spațială, temporală și „verticală”1 - a așanumitelor New Modernist Studies (Mao, Walkowitz 2006, Mao, Walkowitz 2008, Wollaeger, Eatough 2012, Friedman 2015) a stârnit reacții critice intense. „Expansiunea” amintită a fost etichetată ca ,inflație” (Altieri 2012, Collier 2016), ba chiar ca „oportunism” academic (Seaber, Shallcross 2019), de vreme ce, în ultimele decenii, termenul „modernism” s-ar fi transformat într-o strategie de marketing, generând o comodificare masivă a cercetării literare: aproape orice fenomen literar ajunge să fie interpretat ca formă ne(re)cunoscută până atunci a modernismului ${ }^{2}$. Tocmai de aceea, chiar de la început, se impune o precizare metodologică: cele două concepte centrale din cadrul acestui articol - modernismul socialist, respectiv modernismul rural - nu au menirea de a defini paradigme alternative, subversive sau revizioniste. În fapt, le utilizez deoarece, în ciuda sintagmelor aparent oxi-
\end{abstract}

\footnotetext{
* This article was supported by a grant of the Romanian Ministry of Education and Research, CNCS-UEFISCDI, project number PN-III-P1-1.1-TE-2019-1378, within PNCDI III.

${ }^{1}$ Vezi Mao, Walkowitz 2008, p. 738: „Temporal expansion has certainly been important in the study of literary modernism: the purview of modernist scholarship now encompasses, sometimes tendentiously but often illuminatingly, artifacts from the middle of the nineteenth century and the years after the middle of the twentieth as well as works from the core period of about 1890 to 1945 . But the spatial and vertical expansions have been more momentous. Spatial broadening has meant not only that scholars now attend to works produced in, say, Asia and Australia but also that they investigate complex intellectual and economic transactions among, for example, Europe, Africa, the United States, and the Caribbean. In concert with the temporal enlargement, this spatial one has led to an extremely fruitful rethinking of relations among the key terms modernism, modernization, and modernity. Meanwhile, the vertical reconfiguration exerts a kind or degree of disruptive force on modernist studies that it may not on any other period-based field, since for many years modernism was understood as, precisely, a movement by and for a certain kind of high (cultured mandarins) as against a certain kind of low (the masses, variously regarded as duped by the 'culture industry', admirably free of elitist self-absorption, or simply awaiting the education that would make the community of cognoscenti a universal one)".

${ }^{2}$ Vezi Collier 2016, p. 233: „Faced with an apparently nonmodernist artefact - a realist novel, a nature poem in rhyming quatrains, a prose satire with undisguised didactic aims - the new modernist studies offers the typical scholar three paths: (1) ignore it; (2) resign yourself to dissemination in a second-tier journal or the meetings of an ancillary scholarly society; or (3) (most promising, in terms of scholarly prestige) find a way to posit it as representing an unacknowledged modernism, or exemplifying modernism in previously unrecognised ways".
} 
moronice care le compun, ambele dețin potențialul de a activa dimensiuni ale practicilor și ale teoriilor modernismului pe care teoretizările interbelice românești, dar și internaționale, au tins să le obtureze (Dumitru 2016). E vorba de implicațiile sociale, ideologice și culturale ale modernismului, pe care resurecția sa din timpul comunismului le evidenţiază prin excelenţă. Altfel spus, atât modernismul socialist, cât și modernismul rural oferă oportunitatea studierii modernismului (postbelic) românesc prin conectarea substanțială la provocările modernității/modernizării ${ }^{3}$.

\section{Modernismul socialist ca modernism rural}

Utilitatea analitică și istoriografică a conceptului „modernism socialist” a fost recent argumentată convingător de Andrei Terian prin dezvăluirea „mistificărilor” înscenate de teoretizarea neomodernismului. Noțiunea impusă începând cu mijlocul anilor '90 pentru a denumi orientările literare românești dintre (aproximativ) 1965 și 1980 susține iluzia că despărţirea de realismul socialist se petrece într-un context cultural „,neutru”, asemănător celui occidental. În schimb, „modernismul socialist" infirmă posibilitatea unui „metabolism organic” al istoriei culturale naţionale și atrage atenția asupra circumstanțelor ideologice care au modelat revigorarea postbelică a modernismului (Terian 2019, p. 140). Totuși, oricât de revizionist, conceptul dezvoltat de Terian conține și o dimensiune conservatoare: el prelungește tradiția critică locală a receptării literaturii anilor ' 60 și '70 ca subversivă estetic în raport cu sistemul totalitar. Susținut prin exemple extrase mai ales din sfera liricii și fundamentat teoretic prin comparaţia cu modernismul „târziu” (late modernism) manifestat între 1945 și 1965/1970 în culturile literare occidentale (Mellors 2005), modernismul socialist românesc s-ar caracteriza printr-un set de trăsături foarte asemănătoare celor atribuite neomodernismului: ,autonomism estetic (ca opoziție față de ideologia realismului socialist)"; ,transcendență, mit, ermetism (în contrast cu materialismul comunist)”; ,individualism ca alternativă la colectivismul instituționalizat”; „«clasicizarea» modernismului înalt”; ,sensibilitate inaugurală” (Terian 2019, p. 143). Așadar, chiar dacă e deplin integrat în sistemul cultural comunist, modernismul socialist pare a evolua în afara sau împotriva lui, contextul ideologic îndeplinind un rol rezonator mai degrabă decât catalizator.

Ceea ce se pierde astfel din vedere este tocmai acea dimensiune a modernismului românesc postbelic masiv îndatorată regimului instalat după cel de-al Doilea Război Mondial: un modernism dependent, fiindcă era făcut posibil de comunism (și abia ulterior sau numai în plan secund subversiv față de sistemul totalitar). Iar

\footnotetext{
${ }^{3}$ Pentru definirea New Modernist Studies ca recuperare a problematicii modernizării în cadrul studiilor despre modernism, vezi Watson 2019, p. 7: „Putting modernization back into modernist studies entails historicizing modernity and materializing historicism, moving historical inquiry off a strictly intellectual footing to encompass formative elements of social, economic, technological, political, and ecological change".
} 
cel mai simptomatic și mai elocvent exemplu e oferit de romanul cu tematică rurală din epocă, prin intermediul căruia se conturează - ceea ce voi numi în continuare „modernismul rural”. Sintagma dobândește relevanță conceptuală și valoare analitică pe fondul emergenței New Modernist Studies, menționate în deschiderea acestui articol. Evaluarea modernismului ca produs al „modernităţii incomplete" (Jameson 1991, p. 365; Jameson 2002), pornind de la constatarea că tehnicile și practicile moderniste sunt configurate cu precădere în regiunile periferice unde provocările și conflictele modernității dețin un impact mai „virulent”, facilitează implicarea ruralului în dezbatere (Dore 2007; Bluemel, McCluskey 2018). Satul ajunge să fie considerat „matrice și laborator ale modernitătii”” (Watson 2019, p. 42), perspectivă care reactualizează, de fapt, observațiile lui Raymond Williams despre mediul rural ca spațiul în care fenomenele modernizării capitaliste se consolidează înainte de a invada și de a revoluționa urbanul (Williams 1973, p. 49).

O astfel de abordare nici măcar nu e exotică pentru câmpul cultural românesc: încă din 1925, Ștefan Zeletin demonstrează că „singura forță revoluționară, căreia îi datorăm clădirea edificiului nostru modern" a fost constituită în secolul al XIX-lea de clasa „agrarienilor pătrunși de spiritul negoțului” (Zeletin 1991, p. 61). Totuși, în cadrul dezbaterilor ideologice interbelice reflecția asupra modernizării/modernității și, mai ales, asupra modernismului nu a fost niciodată conectată substanţial cu problematizarea ruralității. Raportul a fost mereu disjunctiv, când nu de-a dreptul discriminatoriu (Dumitru 2019).

Corelarea explicită a modernităţii cu ruralul a devenit posibilă în România doar după al Doilea Război Mondial, când regimul totalitar s-a legitimat ideologic și a încercat materializarea proiectului său politic „revoluţionar” prin transformarea alertă și brutală a celei mai numeroase clase sociale locale - cea țărănească. Procesul colectivizării agriculturii (1949-1962), principal suport economic pentru industrializarea masivă a țării, s-a desfăşurat concomitent cu (re)crearea Partidului Comunist, inițial sub numele Partidul Muncitoresc Român (Kligman, Verdery 2015). Astfel se pot explica, pe de o parte, demersurile fără precedent de a îmbina ruralul și modernitatea, și, pe de altă parte, modalitățile variate - adeseori atipice, uneori contradictorii sau chiar autosubminante - prin care sistemul literar românesc a răspuns servituții de a reflecta propagandistic necesitatea proletarizării țărănimii ori de a imagina mediul rural ca avangardă a modernității comuniste.

\section{Traducerea românească a modernismului rural}

Dintre posibilele căi de acces ${ }^{4}$ la înțelegerea ori la interpretarea relației paradoxale dintre ruralitate și modernitate în cadrul regimului comunist $/$ socialist $^{5}$ relevant este cazul traducerilor în limba română ale romanelor cu tematică rurală.

\footnotetext{
${ }^{4}$ Am testat relevanța unor piste de lectură complementare în două studii de caz aflate în curs de publicare: The Faces of Rural Modernity in the Romanian Novel of the Agricultural Collectivization
} 
Conform DCRT ${ }^{6}$, în perioada ante-/interbelică, cu toate că așa-zisa „chestiune țărănească” era clamată de toate partidele politice și de majoritatea orientărilor culturale, subgenul rural este eludat fățiș. Spre exemplu, zecile de fragmente sau de ediţii în limba română din scrierile lui Honoré de Balzac ocolesc cu obstinație tocmai ciclul Scene din viața de la țară (Șuanii - 1829, Medicul de țară - 1833, Preotul de țară - 1839 și Țăranii - 1844). De altfel, până la cel de-al Doilea Război Mondial, doar două traduceri din romane rurale importante sunt publicate, ba chiar și acelea aproape la finalul intervalului, în 1942: John Steinbeck, Fructele mâniei, respectiv Władysław Reymont, Țăranii (deci la peste trei decenii de la apariție și la aproape două de când scriitorul polonez fusese laureat al Premiului Nobel pentru Literatură).

O cu totul altă situație caracterizează epoca postbelică, fiindcă sistemul editorial controlat de stat transformă tematica rurală într-o preocupare constantă, adeseori chiar centrală.

Pe de o parte, motivația principală este, desigur, propagandistică, fapt dovedit și de inflația de reeditări ale traducerilor din romanele lui Mihail Șolohov, un canonic al literaturii realist-socialiste despre colectivizare: Pe Donul liniștit apare în limba română în 1947-1948, apoi în 1949-1950, 1953, 1960, 1963, dar şi în 1986-1987, iar Pământ desțelenit cunoaște zece ediții între 1949 și 1961. Aceeași sferă e completată - alături de numeroasele romane realist-socialiste traduse din limbi estcentral europene - de alte proze sovietice „clasice”, consacrate emancipării aduse de viața în colhoz: de la Cavalerul stelei de aur (1949) și Lumină deasupra pământului (1950) de Semeon Babaevski, la Malul însorit (1950) de Vera Panova, până la Secerişul (1951) de Galina Nikolaeva.

Pe de altă parte, canalizarea ideologică a preocupării pentru ruralitate implică și un efort amplu de restituire a modelelor internaționale sau a tradițiilor regionale ale subgenului rural, pe care recitirile în cheie tezistă pot cu greu să le cuprindă. Sunt recuperați romancieri interbelici maghiari (în 1949, Zsigmond Móricz, Rubedenii), bulgari (în 1950, Krum Velkov, Satul Borovo), polonezi (în 1952, Leon Kruczkowski, Kordian și țăranul), cehi (în 1952, Ivan Olbracht, Proletara) sau slovaci (în 1969, Milo Urban, Biciul viu), cărora, de-a lungul timpului, li se relevă asemănări cu literatura lui Liviu Rebreanu ori a lui Mihail Sadoveanu. Și mai reprezentativă este seria iniţiată la începutul deceniului șapte, adică tocmai în perioada în care colectivizarea agriculturii intrase în cea mai alertă și mai abuzivă etapă (1960-1962), iar formulele dogmatice de reflectare a transformărilor lumii rurale își dovedeau limitele mai mult ca oricând. Chiar în 1960 este tradus pentru prima dată în limba română Tess d'Uberville de Thomas Hardy, adică romanul pe care Raymond

şi Translating Modernism through Communism. William Faulkner and Gabriel García Márquez as Cold War Writers.

5 Pentru o sinteză a controverselor și a aporiilor variației terminologice „,comunism” - ,socialism”, vezi Simuț 2017.

${ }^{6}$ Toate informațiile despre traducerile de roman (ediții, fragmente, foiletoane, receptare critică) utilizate în acest articol sunt extrase din DCRT. 
Williams îl consideră a fi contribuit decisiv la modernizarea literaturii rurale engleze (Williams 1973, p. 182-214). Tess d'Uberville este reeditat în 1962, în 1964 și în 1972, iar un alt roman rural al lui Hardy, Jude Neștiutul, beneficiază de două ediții în 1965 și în 1969. Între timp, în 1962, Țăranii lui Balzac sunt publicați într-o primă traducere în limba română, deci la peste un secol de la apariție. Din faimosul „ciclu țărănesc” balzacian mai apar Șuanii (1971) și Medicul de țară (1972), recuperarea foarte târzie a celor mai importante proze rurale de limbă franceză continuând cu Aimé Pache de Charles-Ferdinand Ramuz (1972) și cu Pământul de Émile Zola (1982 și 1986).

Dezvoltate, așadar, în perioada de maximă intensitate atât a dominației realismului socialist, cât și a campaniei de colectivizare a agriculturii, demersurile de traducere a celor mai prestigioși reprezentanți ai literaturii cu tematică rurală continuă și pe fondul liberalizării din anii '60 și '70. În strânsă legătură cu faptul că regimul comunist a propagat continuu imaginarea țărănimii proletarizate drept o clasă socială modernă și modernizatoare (Radu, Budeancă 2016), scriitorii vremii apelează la toposul/literatura rurală pentru a dobândi

„o mai mare libertate în expunerea interogațiilor [...] la adresa societății sau chiar a regimului; fiindcă puterea e gata să accepte și chiar să autentifice prin documente că în mediul rural transformările revoluționare au un ritm mai lent, împiedicate fiind de conservatorismul habitatului”' (Cordoș 1999, p. 195).

Ruralul și romanul care îl reprezintă își potențează caracterul subversiv nu neapărat „cu voie de la partid”, dar cu siguranță beneficiind și profitând de o platformă ideologică și culturală favorabilă.

Întru totul semnificativ în acest sens este cazul receptării/traducerii romanelor lui William Faulkner, scriitorul cel mai des invocat pentru a confirma legitimitatea literară a modernismului rural, precum și expansiunea sa pe plan mondial (Hubbs 2008). Prima „canonizare” a romancierului american în Franța anilor '30 (Alexandrescu 1969, p. 13-14) are ecouri semnificative în publicistica românească a vremii (vezi BRLR, p. 228), însă nu și un impact notabil asupra literaturii române interbelice ${ }^{7}$. Abia în anii '60 modernismul faulknerian începe să devină cu adevărat influent în România, contextul favorabil acestei schimbări de perspectivă fiind constituit tocmai de mizele ideologice majore ale reconceptualizării universului țărănesc. Primele traduceri se axează pe componentele programatic sociale și vădit rurale din literatura lui Faulkner: în 1961 apare un fragment din Nechemat în țărână (preluat în

\footnotetext{
7 Sugestiv este, în acest sens, fragmentul din secțiunea consacrată lui Camil Petrescu în care Nicolae Manolescu prezintă modelele internaționale ale romanului psihologic românesc: ,psihologismul romanului nostru interbelic are mult mai multe tangențe cu «analiza» de tip franțuzesc (educată la școala clasicilor, a lui Proust și Gide) decât cu investigarea abisurilor ființei umane din romanul rusesc mai vechi sau cu senzualismul metafizic din acela, mai nou, al unui D. H. Lawrence; și încă, e mai legată de luciditatea moraliștilor sau de «răutatea», în fond foarte rațională, a lui Stendhal, decât de unele tentative, ca a lui Faulkner sau a Virginiei Woolf, în aceeași epocă, de a sugera fluiditatea intensă a conștiinței și haloul misterios de impresii în care se învelește ca larva viermelui de mătase în coconul ei” (Manolescu 2008, p. 670).
} 
volumul din 1964), în 1962 este publicat în foileton Conacul (reeditat în 1968, într-o nouă traducere, sub titlul Casa cu coloane), iar în 1967 apare Cătunul. Receptarea critică este tot mai consistentă (Schneider 2008), iar majorității prozatorilor români proeminenți care abordează tematici rurale (Marin Preda, Ștefan Bănulescu, Sorin Titel, D. R. Popescu, Fănuș Neagu ș.a.) li se reliefează afinități cu modelul faulknerian. În acest mod, traducerile românești din scrierile lui Faulkner (completate de reacțiile literare/critice pe care le prilejuiesc) confirmă comentariile lui Pascale Casanova despre „revoluția” culturală produsă de scriitorul american:

„[Faulkner] a făcut să înceteze blestemul rămânerii în urmă a periferiilor, oferindu-le scriitorilor din țările cele mai sărace posibilitatea de a da o formă acceptabilă realităţilor celor mai disprețuite de la marginea lumii. [...] a făcut să acceadă la modernitatea romanescă un univers primitiv și țărănesc, căruia părea să nu i se potrivească decât clasicul realism descriptiv: o civilizație tribală, violentă, îmbibată de mitologia biblică, opusă în totul modernității urbane - face obiectul uneia dintre cele mai mari îndrăzneli formale din secolul al XX-lea" (Casanova 2007, p. 415).

Totodată însă, cazul românesc invită şi la temperarea optimismului ce transpare din evaluările tocmai citate. Dacă inovațiile formale sau succesul de critică (din Franța) ar fi fost suficiente pentru reabilitarea condiţiei culturale a ruralității în (semi)periferiile Europei, atunci Faulkner ar fi trebuit să se impună fie și parțial în anii '30-'40. Or, excepție făcând două traduceri în cehoslovacă, abia perioada comunistă a produs emulația cultural-ideologică necesară consacrării lui Faulkner în Europa de Est (Bahun 2008). Modernismul rural românesc - de inspirație faulkneriană și nu numai ${ }^{8}$ - este mai mult socialist decât estetic: dimensiunea sa subversivă vizează nu doar dogmele literaturii propagandistice imediat contemporane, ci și pe acelea impuse în interbelic prin intermediul cărora modernitatea/modernismul se definește prin disocierea explicită de ruralitate.

$\mathrm{Nu}$ întâmplător, într-un articol de la mijlocul anilor '80, Mircea Iorgulescu subliniază că literatura cu tematică rurală din România ajunge abia în timpul comunismului la faza maturizării depline (prin diversificarea perspectivelor, stilurilor și formulelor narative):

„Pentru proza românească postbelică lumea satului a constituit - şi constituie încă - un univers obsedant: niciodată, în vreuna din epocile anterioare, nu s-a scris despre țărani și despre viața lor atât de mult, atât de insistent, din atâtea perspective. Deși opinia curentă este alta, se poate spune totuşi că şi cantitativ, dar și în aspectele mai profunde, inclusiv în plan valoric, o literatură masivă, compactă a existenței rurale a luat cu adevărat ființă la noi abia în ultimele patru decenii. [...] universul rural încetează să mai fie un spațiu închis, izolat, ostil modificărilor, centripet. Mari forțe centrifuge acționează, îndeosebi asupra

\footnotetext{
${ }^{8}$ Aceeași tendință este confirmată și de asimilarea românească a realismului magic, care s-a manifestat preponderent tot în literatura cu tematică rurală. Corespondentul lui Faulkner este, desigur, Gabriel García Márquez: Un veac de singurătate a fost tradus în limba română în 1971, la doar patru ani de la apariția ediției originale, și a facilitat dezvoltarea rapidă a unei serii ample de proze rurale „garcíamárqueziene”, răspunzând deopotrivă așteptărilor ideologice ale regimului, cât și tendinței de a proiecta satul ca spațiu al subversiunii tipului de modernitate imaginat de comunism.
} 
tinerilor, universul rural devenind un fel de port pentru călătorii (sociale, psihologice) tot mai îndepărtate. [...] Mari mutații se produc [...] după jumătatea deceniului '60-'70, când, într-un alt climat, literatura (re)descoperă istoria contemporană în primul rând prin intermediul schimbărilor petrecute în universul țăănesc" (Iorgulescu 1984, p. 10).

\section{Concluzii}

Așadar, faptul că traducerea lui Șolohov ori a Secerișului Galinei Nikolaeva coexistă cu recuperarea unor ruraliști interbelici est-central europeni precum Zsigmond Móricz sau Leon Kruczkowski, iar reeditările romanelor realist-socialiste canonice despre colectivizare apar cvasi-concomitent cu primele ediții românești din proze rurale prestigioase scrise de Balzac, Hardy sau Faulkner scoate în evidență o dimensiune puțin discutată a câmpului cultural românesc postbelic: interesul (propagandistic al) regimului comunist pentru restructurarea lumii satului facilitează asimilarea unei varietăți de formule romanești rurale fără precedent în literatura română. Metamorfozele sociale dramatice suferite de universul țărănesc în timpul și ulterior procesului de colectivizare a agriculturii activează o ipostază a satului (legitimă și în perioada interbelică, dar preponderent obturată) de reflector privilegiat al provocărilor, al impasurilor și al supliciilor modernizării/modernităţii. Astfel se explică de ce imaginarul rural devine o sursă predilectă pentru desfășurarea unora cele mai inovatoare formule moderniste din literatura română postbelică. Emulaţia creată în jurul traducerii în limba romană a literaturii cu tematică rurală constituie un reper de neocolit pentru înțelegerea și interpretarea unui alt fenomen cultural definitoriu pentru literatura română din timpul comunismului: impactul modelului faulknerian (și, ulterior, al celui garcíamárquezian) asupra romanului rural, adică tocmai consolidarea a ceea ce numeam modernismul (socialist) rural.

\section{SIGLE}

BRLR = Ana-Maria Brezuleanu, Viorica Nișcov, Michaela Șchiopu, Cornelia Ștefănescu, Bibliografia relațiilor literaturii române cu literaturile străine în periodice (1919-1944), vol. II, București, Editura Saeculum I. O., 1999.

DCRT = Dicționarul cronologic al romanului tradus în România de la origini până la 1989, București, Editura Academiei Române, 2005.

\section{ABREVIERI BIBLIOGRAFICE}

Alexandrescu 1969 = Sorin Alexandrescu, William Faulkner, București, Editura pentru Literatură Universală, 1969. 
Altieri 2012 = Charles Altieri, Afterword. How the "New Modernist Studies" fails the Old Modernism, în „Textual Practice”, XXVI, 2012, nr. 4, p. 763-782.

Bahun 2008 = Sanja Bahun, Faulkner, Фолкнер, Folkner, Fokner: A Case-study of SlavicAnglophone Translatability, în „The Faulkner Journal”, 2008, nr. 24, p. 3-19.

Bluemel, McCluskey 2018 = Kristin Bluemel and Michael McCluskey (eds.), Rural Modernity in Britain: A Critical Intervention, Edinburgh, Edinburgh University Press, 2018.

Casanova 2007 = Pascale Casanova, Republica mondială a literelor. Traducere de Cristina Bîzu, București, Editura Curtea Veche, 2007.

Collier 2016 = Patrick Collier, Postscript: Against "Modernist Studies", în Modern Print Artefacts. Textual Materiality and Literary Value in British Print Culture, 1890-1930s, Edinburgh, Edinburgh University Press, 2016, p. 232-238.

Cordoș 1999 = Sanda Cordoș, Literatura între revoluție și reacțiune. Problema crizei în literatura română și rusă a secolului XX, Cluj-Napoca, Biblioteca Apostrof, 1999.

Dore 2007 = Florence Dore, The Modernism of Southern Literature, în Peter Stoneley and Cindy Weinstein (eds.), A Concise Companion to American Fiction 1900-1950, New York, Blackwell Publishing, 2007, p. 228-252.

Dumitru 2016 = Teodora Dumitru, Modernitatea politică și literară în gândirea lui E. Lovinescu, București, Editura Muzeul Literaturii Române, 2016.

Dumitru 2019 = Teodora Dumitru, Social Class Difference and the Evolution of Romanian Literature from Lovinescu's Perspective (1924-1929), în Ștefan Baghiu, Vlad Pojoga, and Maria Sass (eds.), Ruralism and Literature in Romania, Berlin, Peter Lang, 2019, p. 205-218.

Friedman 2015 = Susan Stanford Friedman, Planetary Modernisms: Provocations on Modernity Across Time, New York, Columbia University Press, 2015.

Hubbs 2008 = Jolene Hubbs, William Faulkner's Rural Modernism, în „Mississippi Quarterly”, LXI, 2008 , nr. 3, p. 461-475.

Iorgulescu 1984 = Mircea Iorgulescu, Metamorfozele unei lumi, în România literară, XVII, 1984, nr. 34 , p. 10.

Jameson 1991 = Fredric Jameson, Postmodernism, or The Cultural Logic of Late Capitalism, Durham, Duke University Press, 1991.

Jameson 2002 = Fredric Jameson, A Singular Modernity: Essay on the Ontology of the Present, London, Verso, 2002.

Kligman, Verdery 2015 = Gail Kligman, Katherine Verdery, Țăranii sub asediu. Colectivizarea agriculturii în România (1949-1962). Traducere de Justina Bandol, Iași, Editura Polirom, 2015.

Manolescu 2008 = Nicolae Manolescu, Istoria critică a literaturii române. 5 secole de literatură, Pitești, Editura Paralela 45, 2008.

Mao, Walkowitz 2006 = Douglas Mao and Rebecca Walkowitz (eds.), Bad Modernisms, Durham, Duke University Press, 2006.

Mao, Walkowitz 2008 = Douglas Mao, Rebecca Walkowitz, The New Modernist Studies, în „PMLA”, LXXIII, 2008, nr. 3, p. 737-748

Mellors 2005 = Anthony Mellors, Late Modernist Poetics: From Pound to Prynne, Manchester, Manchester University Press, 2005.

Radu, Budeancă 2016 = Sorin Radu și Cosmin Budeancă (eds.), Countryside and Communism in Eastern Europe. Perceptions, Attitudes, Propaganda, Viena, LIT Verlag, 2016.

Schneider 2008 = Ana Karina Schneider, William Faulkner and the Romanian "Criticism of Survival", în The Faulkner Journal, XXIV, 2008, nr. 1, p. 99-117.

Seaber, Shallcross 2019 = Luke Seaber and Michael Shallcross, The Trouble with Modernism: a Dialogue, în „The Modernist Review”, 2019, nr. 10, https://modernistreviewcouk.wordpress. com/2019/06/28/the-trouble-with-modernism/. Accesat în 20 noiembrie 2020.

Simuț 2017 = Ion Simuț, Literaturile române postbelice, Cluj-Napoca, Editura Școala Ardeleană, 2017.

Terian 2019 = Andrei Terian, Socialist Modernism as Compromise: A Study of the Romanian Literary System, în „Primerjalna književnost”, XLII, 2019, nr. 1, p. 133-147. 
Watson 2019 = Jay Watson, William Faulkner and the Faces of Modernity, New York, Oxford University Press, 2019.

Williams 1973 = Raymond Williams, The Country and the City, London, Oxford University Press, 1973. Wollaeger, Eatough 2012 = Mark Wollaeger and Matt Eatough (eds.), The Oxford Handbook of Global Modernisms, Oxford, Oxford University Press, 2012.

Zeletin 1991 = Ștefan Zeletin, Burghezia română: originea și rolul ei istoric, ediția a II-a, București, Editura Humanitas, 1991.

\section{THE SOCIALIST REINVENTION OF MODERNISM. THE ROMANIAN TRANSLATIONS OF THE RURAL NOVEL (Abstract)}

This study aims at addressing the sizeable interest shown by the post-WWII Romanian literary culture in the translation of rural novels as a telling symptom of the socialist reinvention of modernism. This paper employs two related concept - socialist modernism and rural modernism - in order to show that the cultural phenomenon mentioned above tends to challenge not only the realist socialist dogma of the period, but also the aesthetic reception of modernism assessed in the interwar era and revived in the 1960s. Consequently, the main purpose of the present study is to underline that the Romanian post-war (rural) modernism is more socialist, that aesthetic, meaning that its inception or development is primarily dependent on the communist ideology and literary system, while its subversive dimension ensues from it, or even remains secondary throughout the totalitarian regime.

Cuvinte-cheie: modernism rural, modernism socialist, roman rural, studii despre traducere, comunism.

Keywords: rural modernism, socialist modernism, rural novel, translation studies, communism.

Institutul de Lingvistică și Istorie Literară

"Sextil Pușcariu”al Academiei Române

Cluj-Napoca, str. E. Racoviţă, 21

cosmi_borza@yahoo.com 